\title{
Evaluation of the physical activity level, nutrition quality, and depression in patients with metabolic syndrome: Comparative study: Erratum
}

In the article, "Evaluation of the physical activity level, nutrition quality, and depression in patients with metabolic syndrome: Comparative study", ${ }^{[1]}$ which appeared in Volume 97, Issue 18 of Medicine, the author affiliations appear incorrectly. They should appear as:

İsmet Kazaz, $\mathrm{Msc}^{\mathrm{a}}$, Ender Angın, $\mathrm{PhD}^{\mathrm{a}}$, Seray Kabaran, $\mathrm{PhD}^{\mathbf{b}}$, Gözde İyigün, $\mathrm{PhD}^{\mathrm{a}}$, Berkiye Kırmızıgil, $\mathrm{PhD}^{\mathrm{a}}$, Mehtap Malkoç, $\mathrm{PhD}^{\mathrm{a}}$

${ }^{a}$ Eastern Mediterranean University, Faculty of Health Sciences, Physiotherapy and Rehabilitation Department; and ${ }^{\mathrm{b}}$ Eastern Mediterranean University, Faculty of Health Sciences, Nutrition and Dietetics Department, Famagusta, North Cyprus via Mersin 10, Turkey.

\section{Reference}

[1] Kazaz İ, Ender A, Kabaran S. Evaluation of the physical activity level, nutrition quality, and depression in patients with metabolic syndrome: Comparative study. Medicine. 97;18:e10485. 